\title{
Kink and Everyday Life
}




\title{
Emerald Interdisciplinary Connexions
}

\author{
Series Editors
}

Rob Fisher, Director of Progressive Connexions

M. Susanne Schotanus, Director of Publications

\section{Editorial Board}

Ann-Marie Cook, Principal Policy and Legislation Officer, Queensland Department of Justice and Attorney General, Australia

Teresa Cutler-Broyles, Director of Opportunities and Research, Progressive Connexions

John Parry, Edward Brunet Professor of Law, Lewis and Clark Law School, USA

Karl Spracklen, Professor of Music, Leisure and Culture, Leeds Beckett University, UK

\section{About the Series}

Emerald Interdisciplinary Connexions promotes innovative research and encourages exemplary interdisciplinary practice, thinking, and living. Books in the series focus on developing dialogues between disciplines and among disciplines, professions, practices, and vocations in which the interaction of chapters and authors is of paramount importance. They bring cognate topics and ideas into orbit with each other while simultaneously alerting readers to new questions, issues, and problems. The series encourages interdisciplinary interaction and knowledge sharing and, to this end, promotes imaginative collaborative projects which foster inclusive pathways to global understandings. 


\title{
Kink and Everyday Life: Interdisciplinary Reflections on Practice and Portrayal
}

\author{
EDITED BY
}

KYLO-PATRICK R. HART

Texas Christian University, USA

And

TERESA CUTLER-BROYLES

University of New Mexico, USA

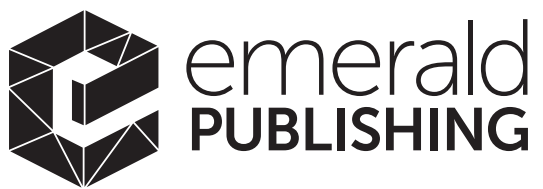

United Kingdom - North America - Japan - India - Malaysia - China 
Emerald Publishing Limited

Howard House, Wagon Lane, Bingley BD16 1WA, UK

First edition 2021

Editorial matter and selection copyright (C) Kylo-Patrick R. Hart and

Teresa Cutler-Broyles, 2021

Published under an Exclusive Licence by Emerald Publishing Limited

Individual chapters copyright (C) 2021 Emerald Publishing Limited

\section{Reprints and permissions service}

Contact: permissions@emeraldinsight.com

No part of this book may be reproduced, stored in a retrieval system, transmitted in any form or by any means electronic, mechanical, photocopying, recording or otherwise without either the prior written permission of the publisher or a licence permitting restricted copying issued in the UK by The Copyright Licensing Agency and in the USA by The Copyright Clearance Center. Any opinions expressed in the chapters are those of the authors. Whilst Emerald makes every effort to ensure the quality and accuracy of its content, Emerald makes no representation implied or otherwise, as to the chapters' suitability and application and disclaims any warranties, express or implied, to their use.

\section{British Library Cataloguing in Publication Data}

A catalogue record for this book is available from the British Library

ISBN: 978-1-83982-919-2 (Print)

ISBN: 978-1-83982-918-5 (Online)

ISBN: 978-1-83982-920-8 (Epub) 


\section{Table of Contents}

About the Contributors vii

List of Figures ix

List of Contributors $x i$

Introduction: Kink and Our Everyday Lives xiii

Kylo-Patrick R. Hart

Reflections on Practice: From Suspension Hooks to College Hookups

Chapter 1 Kink-Space and the Body: Transforming the Liminal

Teresa Cutler-Broyles

Chapter 2 Creating Spaces, Maintaining Places for

Male-on-Male Kink

Nick J. Mulé

Chapter 3 United Collars of BDSM: Critical Exploration of Changes in the New BDSM Scene in a Postcommunist Environment

Lucie Drdová and Adéla Mölzer Hrabáková

Chapter 4 There Has to Be a Better Way: Kink-ifying Campus Culture to Overcome Communication Challenges 


\section{Reflections on Portrayal: From Victorian Porn to Contemporary Media}

Chapter 5 Kink in the Time of Sexology: An Interdisciplinary Approach to "Abnormal Sexuality" in Victorian Culture

Lorraine Rumson

Chapter 6 Ooh, Shiny! From Catwoman and Mrs. Peel to the Latex Submissive

Jeremy Vaughan

Chapter 7 Kinky Sex Lives and Groundbreaking (Exploitation) Cinema

Kylo-Patrick R. Hart

Chapter 8 Healing the Image: A Conceptual Investigation of the Healing Narrative in Cultural Representations of BDSM

M. Susanne Schotanus

Conclusion: Kink and the Way Forward

Teresa Cutler-Broyles

Index 


\section{About the Contributors}

Teresa Cutler-Broyles has a master's degree in Cultural Studies and a master's certification in Architectural Historic Preservation. She is a professional writer, published on a wide variety of subjects in both fiction and nonfiction venues. She teaches Film and Cultural Analysis at the University of New Mexico (USA), is Director of Opportunities and Research at Progressive Connexions (UK), and is the Resident Director for a study abroad program in Perugia (Italy). Her research interests include architecture, circuses, cultural theory, dance, film theory, gardens, historical preservation, Italy and Italian history, performance, science fiction (especially Star Trek), sexuality and gender, travel, and vampires and other creatures of the night.

Lucie Drdová ( $\mathrm{PhD}$, Masaryk University) is a recent graduate of $\mathrm{PhD}$ studies in the Department of Sociology at Masaryk University in Brno (Czech Republic). Her research interests include ethnography, gender, identities, marginalized groups, and subcultures. She has published articles on virtual ethnography, virtual identities, current legislation regarding BDSM practices, the development of contemporary BDSM subculture, and the conception of BDSM in Fifty Shades of Grey.

Kylo-Patrick R. Hart (PhD, University of Michigan) is Chair of the Department of Film, Television, and Digital Media at Texas Christian University (USA), where he teaches courses in film and television history, theory, and criticism and queer media studies. He is the author of several books about media (including The AIDS Movie: Representing a Pandemic in Film and Television and Queer Males in Contemporary Cinema: Becoming Visible), founding coeditor of the academic journal Queer Studies in Media \& Popular Culture, and a recipient of the AEJMC Lesbian, Gay, Bisexual, Transgender, Queer Interest Group Leroy F. Aarons Award for Lifetime Contributions to LGBTQ Education and Research.

Adéla Mölzer Hrabáková studied Culturology and Anthropology at Charles University in Prague (Czech Republic). A BDSM enthusiast, she also likes to explore human sexuality from theoretical and philosophical points of view. Currently, she organizes BDSM events in the Czech Republic with a group that represents the "new scene." She focuses primarily on role-playing aspects and how they affect practitioners' behaviors.

Nick J. Mulé (PhD, University of Manchester) is an Associate Professor in the School of Social Work, cross-appointed to the Faculty of Health and the School 
of Gender, Sexuality and Women's Studies, and is Coordinator of the Sexuality Studies Program at York University in Toronto, Ontario (Canada). His research interests include the social inclusion/exclusion of LGBTQ populations in social policy and service provision and their recognition as distinct communities in cultural, systemic, and structural contexts. He also engages in critical analysis of the LGBTQ movement and the development of queer liberation theory.

Lorraine Rumson has an MA in English Studies from the Freie Universität Berlin (Germany), with a concentration in Victorian literature. Her MA research concerns femininity and modernity in Victorian Jewish writing, and she is currently working on her $\mathrm{PhD}$ at the Freie Universität Berlin on Victorian Jewish Medievalism. She has presented on Victorian porn at conferences in Austria and the Czech Republic, and has been interviewed on the subject for Canadian radio. She is the Network Coordinator for Progressive Connexions and editor-in-chief of the Berlin-based independent literary journal FU Review.

M. Susanne Schotanus is an Independent Researcher with a master's degree in Research in Cultural Analysis from the University of Amsterdam (Netherlands). Her work has focused on alternative sexual practices and relationship structures, especially forms of kink and BDSM. She aims to show how BDSM practices are an inherent part of Western culture, in that they share some of the same foundational concepts. She is currently a mentor in the CARAS program and involved in the production of several edited volumes on the topics of kink and BDSM, as both contributor and editor.

Noelle Summers received master's degrees in Social Work and Social Policy from Washington University in St. Louis (USA), specializing in sexual health and its intersections with social justice. She has cofacilitated several courses at the university's Brown School of Social Work, including Designing and Implementing Sexual Health Education and Regulating Sex, and has presented across the globe at conferences on Consent and Communication. She is interested in applying kink frameworks to increase sexual self-efficacy on campus, increasing access to reproductive health care, and holistic sex education through policy change.

Jeremy Vaughan, an Independent Researcher (Netherlands), has spent most of his life educating. His multifaceted background has put him in advisory roles for engineering firms, museums, libraries, and other educational resources. $\mathrm{He}$ received his MFA from Tufts University and the School of the Museum of Fine Arts, an interdisciplinary program that utilizes Tufts' academic programs and the Museum school's cross-disciplined studio practice. His book Stop Me If You've Heard This Before is a self-reflective analysis of travel and relationships. 


\section{List of Figures}

Figure 4.1. The Hookup Card.

Figure 5.1. A Plate from the Medical Book The Silent Friend (Perry \& Perry, 1847, p. 84). 
This page intentionally left blank 


\section{List of Contributors}

Teresa Cutler-Broyles University of New Mexico, USA and the Umbra Institute, Italy

Lucie Drdová Masaryk University, Czech Republic

Kylo-Patrick R. Hart Texas Christian University, USA

Adéla Mölzer

Hrabáková

Independent Researcher, Czech Republic

Nick J. Mulé

York University, Canada

Lorraine Rumson

Freie Universität Berlin, Germany

M. Susanne Schotanus

Independent Researcher, Netherlands

Noelle Summers

Washington University in St. Louis, USA

Jeremy Vaughan

Independent Researcher, Netherlands 
This page intentionally left blank 


\section{Introduction: Kink and Our Everyday Lives}

Kylo-Patrick R. Hart

Keywords: Aftercare; BDSM; deviancy; inclusivity; negotiation; nonnormativity

In March 2019, two dozen presenters gathered in Prague, Czech Republic, for an inclusive interdisciplinary conference pertaining to kink in relation to sexuality and technology. This two-day event was organized to explore the numerous ways that kink is practiced regularly in people's lives as well as portrayed in media offerings of different kinds. Its sessions focused on topics including fetishes, kink histories and narratives, kink spaces, pornography, sex work, and sexuality in a digital world.

Over the course of those eye-opening two days, most participants encountered ideas they had never before thought about - or perhaps never before felt comfortable thinking about. At least in part, that is because kink is a topic that has not typically been encountered in mainstream society even though, as my coeditor Teresa CutlerBroyles notes in her conclusion to this volume, it has been common to many individuals' sexual behaviors for as long as people have been having sex. Different historical eras define what is to be regarded as normal or abnormal, socially acceptable or deviant, with kinky ways of behaving and being historically falling closer to the abnormal/deviant ends of those binary oppositional spectra. However, all of that is starting to change more and more, as kink in the twenty-first century becomes increasingly visible in a wider range of the world's cultures than ever before. Accordingly, the goal of many of the conference participants, as Cutler-Broyles notes, was to collectively endeavor to demystify and destigmatize the concept of kink by candidly articulating and investigating its numerous dimensions - with regard to both practice and portrayal - during our time together in Prague, explorations that have continued long after we all returned to our respective home countries.

By the time the conference concluded, it became evident that many students, researchers, practitioners, and others with personal and professional interests in kink would benefit from an edited volume offering an overview of global perspectives, research approaches and findings, and best practices pertaining to this topic. This is that book. All of its chapters, written by a subset of the conference participants, have grown out of that interdisciplinary gathering. However, from the very beginning, all of the chapter authors were well aware that this book is not a set of conference proceedings. Instead, we collaborated during the early planning stages to ensure that we used the original conference presentations as preliminary starting points for chapters that have blossomed substantially, both in 
content and complexity, in the many months since then to form a coherent, fulfilling volume on this truly intriguing topic.

\section{Dynamics of Kink and Everyday Life}

As the various conference presentations revealed, the term "kink" connotes different things to different people. For some, hearing this word calls to mind images of deviancy and depravity. For others, it generates excitement for sexual activities and ways of being that are regarded by many as nonnormative, yet are enjoyable and often empowering for those who choose to engage in them. The term was derived from notions of a "bend" in an individual's sexual practices or desires, which leads one away from conventional (or so-called "vanilla") forms of sexual expression in favor of engaging regularly in more unconventional ones, including BDSM (a classification category encompassing bondage and discipline, dominance and submission, and sadism and masochism) and fetish activities. "According to a large-scale survey a decade ago by Susan Wright," notes SavinWilliams (2019), "the most frequent kink behaviors engaged in by $75 \%$ to $90 \%$ of practitioners were bondage, discipline, dominance, submission, spanking, leather, role-playing, exhibitionism, polyamory, clothing fetish, and voyeurism" (para. 2).

Kink has evoked an array of cultural responses over time, ranging from curiosity to disgust, arousal to fear. Nevertheless, it has simultaneously experienced an intriguing expansion in popularity and increasingly surrounds us in our everyday lives, even among individuals who opt not to participate in kinky activities as part of their own sex lives. Most people encounter kink regularly nowadays - whether in films, television series, works of literature, preferred sex establishments, or their own bedrooms - and the range of its potential activities and their variations is quite broad. Consider, for example, entries from the scrolling list of kinky practices and potential choices of relevance to them that appears on-screen during the opening moments of director Rupert Everett's 1996 film, Skin \& Bone, about the daily lives of three male sex workers in Los Angeles. Options pertaining to bondage include "precede by humiliation," "verbal count of blows," "gleeful, amused sadist," and "turned on, aggressive sadist." Options pertaining to spanking and flogging include "blacksnake," "bullwhip," "cat o" nine tails," and "schoolboy cane." Options pertaining to tolerance include "no marks," "welts," "long-term bruises," and "painful, month-long bruises." Options pertaining to flesh mementos include "no blood or scars," "scars OK," "scars desired," and "lots of blood."

In addition to BDSM, kink in our everyday lives can take the forms of experimentation, fetishism, gender bending, group sex, performativity, public sex, and sexual role-playing, among many others. It is quite impressive, therefore, that director Gregg Araki, in the combined offerings of his teen-apocalypse trilogy during the decade of the 1990s (i.e., 1993's Totally F***ed Up, 1995's The Doom Generation, and 1997's Nowhere), explicitly included references to and representations of all of the following kinky phenomena: ass play, body shaving, bondage, diaper play, discipline, dominance, enema play, erotic humiliation, face-sitting, fetishism, fisting, fun with sex toys, golden showers, group sex, paraphilic 
infantilism, public sex, rimming, sadomasochism, sexual fluidity, spanking, submission, voyeurism, and even the occasional turkey-baster insemination party. In this regard, it is important to note that Araki intentionally incorporated such phenomena in his creative output at a time when they were only quite rarely encountered in U.S. cinematic offerings. In doing so, he endeavored intentionally to acknowledge the existence of, and destigmatize, such kinky activities, helping to pave the way for the growing number and range of kinky representations on film that have begun to appear more frequently since then. It is further impressive that, while doing so, Araki refrained from imposing any sort of moral judgment on these various on-screen activities as they unfolded, providing no guidance whatsoever as to how individual viewers should regard or respond to them (Hart, 2013).

At its core, kink requires "negotiating with a prospective partner before anything happens. If that negotiation is done right, it's more like a collaboration toward a common goal: each party's pleasure" (Yu, 2019, para. 9). This negotiation process simultaneously enables participants to overcome the socialization message that it is shameful to ask for what one desires sexually and helps to ensure, in most instances, that they do not experience any unwelcome violations of consent ( $\mathrm{Yu}, 2019)$. Aftercare - the physical and emotional caretaking that enables participants to reset their equilibrium and readopt their everyday roles in relation to one another - is also an essential component of any kinky sexual encounter (Jones, 2020, para. 5).

Researchers have found that kink can provide safe spaces for individuals of all kinds to establish and experience inclusive environments; it can also enable members of marginalized communities (such as trans people) to become more comfortable in their relationships with their own bodies and with others (Desai, 2019). In addition, research has shown that many individuals who embrace and indulge in kink tend to be less neurotic, more extroverted, less rejection-sensitive, and more open to experiencing new things than those who do not (Aswell, 2019; Hers, 2020). It is important to note, however, that kink is experienced quite differently by different people - what is regarded as kinky by some may be considered ordinary or "vanilla" by others. Along these lines, the editorial team of "A Beginner's Guide to Kink" point out:

Kink is usually looked at through the lens of what a given culture
or society deems normal, but it's also relative to each couple and
individual. If the missionary position seems foreign to you, but you
don't think twice about using blindfolds, missionary could be
defined as one of your kinks. (Hers, 2020, para. 2)

This means the many manifestations of kink are regarded and experienced differentially by a wide range of participants, at least in part because significant differences exist within and among societies and cultures when it comes to conceptions of human sexuality (Patton, 1991). Despite those important realities, a recent survey nevertheless found that nearly half of its respondents were interested in kink, even if they have not yet explored it themselves (Aswell, 2019). 


\section{Analyzing Kink in Everyday Life}

This book explores kinky sexual phenomena (past and present) as experienced in bathhouses, circuit clubs, dark rooms, fetish clubs, hookup culture, pornography, sex shops, and other domains and as represented in literature, film, and television. Acknowledging that individuals outside the kink scene continually make assumptions about its practices and participants that are based heavily on fictional discourses rather than factual realities, it is intended, at least in part, to challenge such uninformed, inaccurate, and frequently deleterious notions. In doing so, it serves also to demonstrate how nonnormative sexual activities and ways of being constitute healthy expressions of human sexuality for an increasingly wide range of individuals and contribute to ever-evolving notions of inclusivity and acceptance. For as Savin-Williams (2019) emphasizes:

In the public mind, kink is often equated with "weird sex," which they don't understand and usually don't approve of. However, it is critical from a kink perspective that what kinksters do is not just about sex but, more importantly, about enhancing intimacy between partners. Thus, kink is usually a partnered rather than a solo activity. (para. 4)

The first four chapters in this collection, grouped under the heading "Reflections on Practice: From Suspension Hooks to College Hookups," explore everyday experiences and manifestations of kink that result in exciting, safe, and healthy expressions of human sexuality. Their topics span the center and the fringes of the kink community, offering insights into a world in which kink is no longer regarded as being dangerous, deviant, or perverse.

The first chapter in this section, "Kink-Space and the Body: Transforming the Liminal" by Teresa Cutler-Broyles, analyzes a 2019 BDSM performance, by Maegan Machine, as a performative event that occurs within a particular "kinkspace." It demonstrates how instances of such ritualistic performance frequently render established understandings of kink power dynamics obsolete and, in this specific case, can serve as a powerful expression of women's oppression in a patriarchal society.

Next, in his chapter "Creating Spaces, Maintaining Places for Male-on-Male Kink," Nick J. Mulé articulates the significance and importance of establishing and maintaining places where male-on-male sexual activity on the premises can regularly occur. In doing so, he focuses on the role that backspaces play in enabling individuals to present different sides of themselves in different contexts (including, in relation to his argument, bathhouses, circuit clubs, dark rooms, and porn theaters) and the centrality of male-on-male subaltern spaces and places in serving as fantasy-based alternatives to the monotony of everyday life.

From there, Lucie Drdová and Adéla Mölzer Hrabáková, in their chapter "United Collars of BDSM: Critical Exploration of Changes in the New BDSM Scene in a Postcommunist Environment," endeavor to address the dearth of kink research devoted to postcommunist countries and contexts by focusing on the 
establishment and ongoing evolution of a BDSM subculture in the postcommunist Czech Republic. They reveal how the contemporary BDSM subculture in that country is far more diverse today than in past decades and substantially reflects the current generation's mindset.

Rounding out the contents of this first group of chapters is "There Has to Be a Better Way: Kink-ifying Campus Culture to Overcome Communication Challenges" by Noelle Summers. In it, she argues that use of an intervention called the Hookup Card can enable college students to experience more positive outcomes of their casual sexual encounters, whether kinky or otherwise.

The additional four chapters in this collection, presented under the heading "Reflections on Portrayal: From Victorian Porn to Contemporary Media," identify ways that kink culture generally, as well as various of its subcultures, have been represented in a range of media offerings over time. They demonstrate how conceptions of kink continue to evolve and how media portrayals of kink can potentially - and actually - impact audience members in different historical eras and stages of life.

In "Kink in the Time of Sexology: An Interdisciplinary Approach to 'Abnormal Sexuality' in Victorian Culture," Lorraine Rumson explores how contemporary reactions to kinky sexual activities are rooted in categories that emerged in the legal and medical discourses of the Victorian era. In addition, she examines representations of nonnormative sexual practices in noteworthy literary offerings of Victorian pornography.

In "Ooh, Shiny! From Catwoman and Mrs. Peel to the Latex Submissive," Jeremy Vaughan applies concepts of objectification, fetishism, and the aura to the pervasive phenomenon of shiny bodies in the kink aesthetic. He utilizes an interdisciplinary approach to reflective practice, involving personal reflections from different stages of his life combined with noteworthy viewing experiences of different media offerings over time, to cultivate a clearer understanding of the appeals of shiny objects and bodies to audience members of all ages.

In my own chapter, "Kinky Sex Lives and Groundbreaking (Exploitation) Cinema," I analyze the contents of two groundbreaking cinematic offerings Cruising (1980, directed by William Friedkin) and Feed (2005, directed Brett Leonard) - that depict kinky sexual activities and ways of being, and were targeted primarily to mainstream audience members, at historical moments when doing so was highly atypical. In the process, I demonstrate how both of these films, as a result of their exploitative approaches to representing their chosen subject matter during their respective historical moments, likely ended up doing far more representational harm than good when all was said and done.

Finally, in "Healing the Image: A Conceptual Investigation of the Healing Narrative in Cultural Representations of BDSM," M. Susanne Schotanus problematizes the concept of the "healing narrative" when it is applied to both BDSM practices and media offerings that represent them. More specifically, she explores the concept of "healing" in relation to relevant representations contained in the feature-length film Secretary (2002, directed by Steven Shainberg) and the Showtime cable television series Billions (2016-present). 
As sexual-health consultant Francisco Ramirez explains:

Kink is anything that falls outside the bounds of culturally defined expectations, which, because of often wildly puritanical societies, could basically be anything that's not penile-vaginal intercourse. [...] Whether you have kinks or fetishes or both or none, remember that all options can be perfectly healthy so long as sexual events are consensual and enjoyable for all parties involved. (Mandriota, 2019, para. 5, 10)

Accordingly, when considered both individually and collectively, the chapters in this collection demonstrate how kinky activities and ways of being are not only "normal" but also becoming the norm for the many individuals who regard them as empowering, exciting, healthy, liberating, safe, and stimulating expressions of their sexuality. It is hoped they will provide practitioners, scholars, and others with an understanding of past and present approaches to thinking about and analyzing kink and inspire new avenues of exploration in this intriguing area of interpersonal, sexual, and research activity.

\section{References}

Aswell, S. (2019, October 10). 1 in 5 of your friends is getting kinky-should you be too? Healthline. Retrieved from https://www.healthline.com/health/healthy-sex/ kinky-sex-bdsm

Desai, R. (2019, August 7). The psychology of sexual kink. The Swaddle. Retrieved from https://theswaddle.com/what-is-kink-the-psychology-behind-sexual-behavior/

Hart, K. R. (2013). Queer males in contemporary cinema: Becoming visible. Lanham, MD: Scarecrow Press.

Hers Editorial Team. (2020). A beginner's guide to kink. Retrieved from https:// www.forhers.com/blog/a-beginners-guide-to-kink

Jones, A. (2020, August 6). Your guide to BDSM aftercare, according to a sex therapist. Women's Health. Retrieved from https://www.womenshealthmag.com/ sex-and-love/a33397578/bdsm-aftercare/

Mandriota, M. (2019, November 14). What's the real difference between a fetish and a kink? Well+Good. Retrieved from https://www.wellandgood.com/what-is-kinkand-fetish/

Patton, C. (1991). Visualizing safe sex: When pedagogy and pornography collide. In D. Fuss (Ed.), Insidelout: Lesbian theories, gay theories (pp. 373-386). New York, NY: Routledge.

Savin-Williams, R. C. (2019, January 22). What is kink? Psychology Today. Retrieved from https://www.psychologytoday.com/us/blog/sex-sexuality-and-romance/201901/ what-is-kink

Yu, M. (2019, June 1). How to talk about sex (and consent): 4 lessons from the kink community. NPR. Retrieved from https://www.npr.org/sections/health-shots/ 2019/06/01/728398532/how-to-talk-about-sex-and-consent-4-lessons-from-the-kinkcommunity 